\title{
Fibrin glue is a quick and effective treatment for primary and recurrent pilonidal sinus disease
}

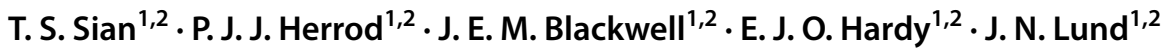

Received: 17 May 2018 / Accepted: 30 September 2018 / Published online: 9 November 2018

(c) The Author(s) 2018

\begin{abstract}
Background Pilonidal sinus disease (PSD) is a common, chronic inflammatory condition involving hair follicles within the natal cleft. It mainly affects young males and creates a significant health, social and economic burden. Traditional surgery is often radical resulting in pain, wound complications, long recovery times and poor cosmesis. The aim of our study was to evaluate fibrin glue as a primary treatment for PSD.

Methods Fibrin glue procedures for a single surgeon at our institution were identified from operative coding databases and the logbook from January 2011 to January 2016. Patients had curettage of the sinus with fibrin glue obliteration. Recurrence data was collected retrospectively.

Results One hundred and forty-six patients were identified; (115 (79\%) males, mean age 30 (range 16-78 years). One hundred and forty-four (99\%) were discharged the same day. Four $(2.7 \%)$ were treated conservatively for wound discharge. Median operating time was 9 (range 4-28) min. There were 40 (27\%) recurrences after one glue application. Median time to recurrence was 4 (range $0.25-36$ ) months. Twenty-four (60\%) of the recurrences had repeat glue treatment with 4 (16.6\%) recurrences. After 2 rounds of treatment with glue alone, 126 out of 130 (96.9\%) patients had healed.

Conclusions Fibrin glue application following curettage of the sinus is a quick and effective procedure for first and second line treatment of PSD.
\end{abstract}

Keywords Pilonidal sinus $\cdot$ Fibrin glue $\cdot$ Ambulatory surgical procedures $\cdot$ Minimally invasive surgical procedures

\section{Introduction}

Pilonidal sinus disease (PSD) is often a chronic and recurring condition in younger people, having a significant impact on social life, work and self-image. The reported incidence is 26 per 100,000 , with a ratio of approximately $3: 1$ (male: female) at a mean age of $30[1,2]$.

The aetiology of PSD remains unclear. Earlier theories of a congenital cause led to the practice of wide excisional surgery with great tissue loss. Recent evidence [3-5] and studies using the electron microscope have suggested that the majority of hairs found in pilonidal sinuses are cut or

T. S. Sian

t.sian@nhs.net

1 Division of Medical Sciences and Graduate Entry Medicine, University of Nottingham, Derby, UK

2 Department of Colorectal Surgery, Royal Derby Hospital, Derby Teaching Hospitals NHS Foundation Trust, Uttoxeter Road, Derby DE22 3NE, UK shaved hairs originating in the occiput $[6,7]$. This has led to the development of more minimally invasive, endoscopic and even non-surgical techniques [8-11]. Despite many previous studies reporting varying recurrence outcomes, no consensus exists as to the best intervention for PSD. The ideal treatment of PSD should provide a high chance of cure with a low recurrence rate and minimal tissue loss [12] whilst avoiding inconvenience for the patient and situations, where the treatment is worse than the disease [13].

Incision and drainage in acute disease can provide a longterm cure but up to half of the patients will return with recurrent chronic symptoms [14, 15]. A 2010 Cochrane Review concluded that there was no overall benefit of wide excision and healing by secondary intention over primary closure; healing by secondary intention, whilst having a lower rate of recurrence is associated with significantly longer wound healing times and higher pain levels $[16,17]$. Lateral closure techniques are better than midline closure, flattening the natal cleft, making the local environment less conducive to infection and recurrence [18]. Where there is substantial 
involvement or scarring following previous surgery, excision and secondary healing or flap reconstruction was preferred [16]. That so many techniques are described suggests that the use of a particular one is more than often decided by surgeon preference rather than evidence [18].

These more radical procedures are associated with a recurrence rate of up to $18 \%$ [19]; however, they often involve significant tissue loss, need for wound care, a high wound breakdown rate, prolonged pain and immobility [20-22]. Keshava et al., reported a $38 \%$ superficial wound breakdown and $8.4 \%$ complete wound breakdown rate, with a median time to heal of 80 and 84 days, respectively, following the Karydakis procedure [23]. Keshvari et al., reported a wound complication rate of $18.7 \%$ and a median time to heal of 16 days for the same procedure [24].

Minimally invasive surgical procedures and chemical therapies have, therefore, become more popular [21, 25-27]. Although these procedures have a higher reported primary recurrence rate of over 20\% [22], they fulfil the other criteria outlined by Allen-Mersh, with rapid return to normal activity being an attractive outcome [5,28]. Repeat application is simple and has an overall cure rate of over $90 \%$ [16].

Fibrin sealants have been used in a variety of surgical procedures including fistula-in-ano, repairing dural tears, bronchial fistulas, corneal transplantation and for achieving haemostasis after abdominal trauma [29]. They mimic the final stages of the coagulation cascade; thrombin cleaves the fibrinogen chains to produce a physiologic fibrin clot, independent of the patient's coagulation pathways [29]. The fibrin clot degrades over time by natural fibrinolysis, stimulating macrophages and promoting collagen production at the wound site which allows tissue healing [20,29].

Our group was the first to use fibrin glue as primary treatment of PSD in a pilot study in the early 2000s [30]. It has since been used in adults and children in relatively small numbers of patients with PSD [25, 27, 28, 31]. The benefits reported include a rapid return to normal activities, high patient satisfaction no requirement for aftercare and a significant cost benefit over other techniques [21, 25, 27, 28, 32]. Outcome in larger numbers of patients is lacking, however. The aim of the present study was to further evaluate fibrin glue as primary treatment for PSD.

\section{Materials and methods}

\section{Patient selection}

Fibrin glue procedures performed by a single operating surgeon at Royal Derby Hospital, Derby, UK, were identified from prospective operative coding databases and the logbook from January 2011 to January 2016. Patients with multiple natal cleft pits with or without secondary tracts opening away from the midline were offered fibrin glue, as were patients with recurrence after any previous excisional, primary closure or flap procedure or recurrence after previous glue treatment. Four patients who attended for glue application had infected sinus on the day of operation and had incision and drainage instead. One of these had recurrence later treated with glue. Two patients were not offered treatment with glue because of excessive scaring after multiple operations for PSD and associated chronic induration caused by low-grade sepsis in the extensive sinus complexes. Both of these patients were successfully treated with rhomboid flap.

Each patient treated with fibrin glue was followed for at least 1 year postoperatively.

\section{Operative technique}

All procedures were performed as same day discharge under general anaesthesia with one exception: a patient who was classified American Society of Anaesthesiologists (ASA) grade 3, who was treated under local anaesthesia. Patients were operated upon in the left lateral position with the upper buttock retracted using tape to open the natal cleft to facilitate access. No antibiotic prophylaxis was given.

Tracts were delineated using a blunt fistula probe (Fig. 1). Sinuses were then meticulously curetted using a Volkmann's spoon (Fig. 2) to remove any hair and granulation tissue (Fig. 3). The tract was then flushed with saline to clear any further debris loosened but not yet removed. The glue application system containing the pre-mixed glue was inserted to the hilt into the tract and then fibrin glue (Tisseel ${ }^{\mathrm{TM}}$, Baxter [33]) injected to obliterate the sinus, withdrawing slowly as the glue was injected (Fig. 4). If long tracts were present, then the range of the applicator was extended by substituting the tip for a 21 -gauge cannula sheath and inserting that to the hilt before applying the glue as above. Filling of the sinuses with glue was

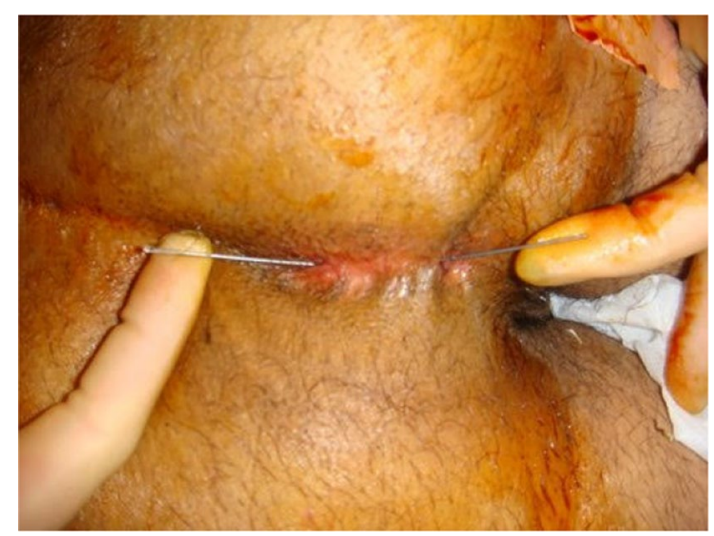

Fig. 1 Identification of tract with blunt probe 


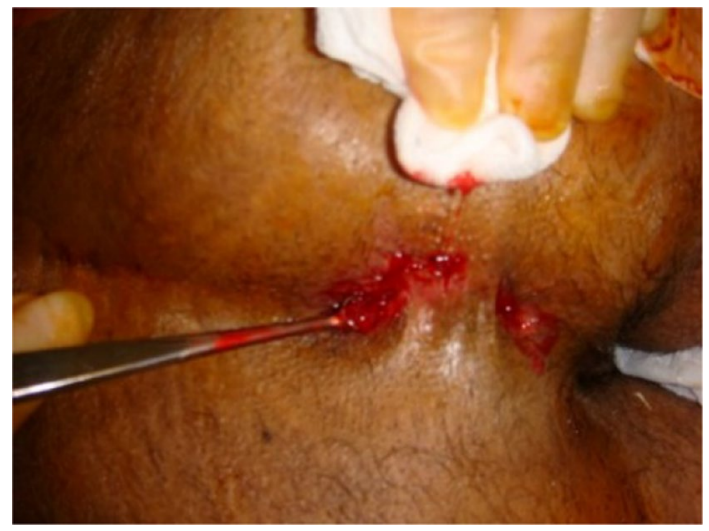

Fig. 2 Curettage with Volkmann's spoon

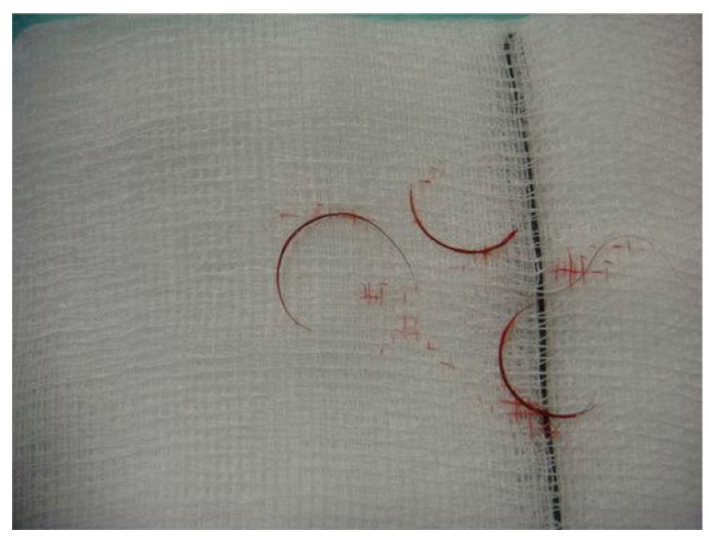

Fig. 3 Extracted hair

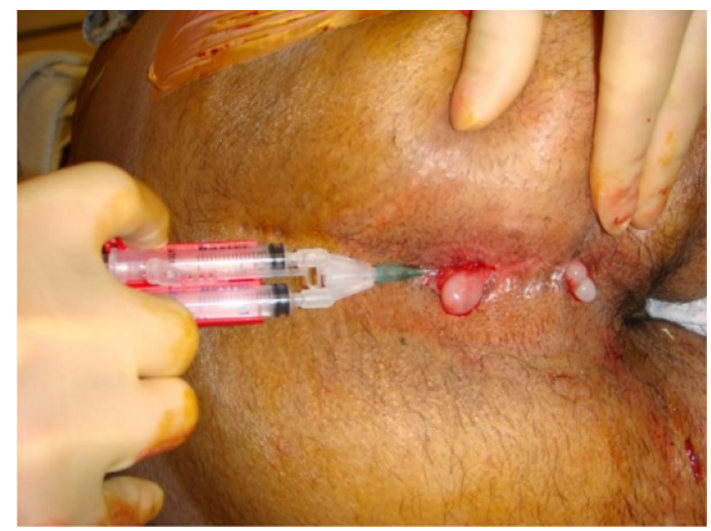

Fig. 4 Filling of sinus with Fibrin glue

assumed to be complete when excess glue appeared at all of the external sinus openings (Fig. 4). The glue was then allowed to set (approximately $40 \mathrm{~s}$ ) before any excess was trimmed flush to the skin using scissors. No further dressing was required.
Patients were discharged with oral paracetamol to be taken as required. They were advised to bathe normally, to maintain good personal hygiene of the treated area and told that they should return to full normal activities within 2-3 days or sooner if they felt able. They were also warned that sometimes there is a clear discharge of tissue fluid from the glued sinuses. Review was scheduled for 3 months postoperatively. Where there was complete healing, patients were discharged. Further follow-up was arranged if there was continued discharge from the wound or signs of infection but not needing drainage.

In the case of recurrence, patients were advised to either present to hospital in the case of emergency or to their general practitioner for re-referral to the operating surgeon if they had already been discharged after initial review at 3 months. All options from conservative management, repeat glue, off-midline flap closure or wide excision and healing by secondary intention were once more discussed.

\section{Results}

Of the 146 patients identified, 115 (79\%) were male with a median age of 28 (range 16-78) years (Table 1). Nineteen had had previous operative treatment for PSD: incision and drainage $(n=9)$, flap procedures $(n=6)$, excision and packing $(n=2)$ and excision and midline closure $(n=2)$. Following the first glue application, 144 (99\%) patients were discharged on the day of the procedure and the remaining 2 the next day. Median operating time was 9 (range 4-28) min. Four $(2.7 \%)$ patients were treated conservatively for clear discharge through the sinus post-procedure. There were $40(27 \%)$ recurrences after 1 glue application. The median time to recurrence after initial glue treatment was 4 (range

Table 1 Patient demographics

\begin{tabular}{ll}
\hline Variable & Outcome $n(\%)$ \\
\hline Gender & \\
Male & $115(78.8)$ \\
Female & $31(21.2)$ \\
Age & $28(16-78)^{\mathrm{a}}$ years \\
Previous surgery & $19(13 \%)$ \\
Operative time & $9(4-28)^{\mathrm{a}}$ min \\
Wound discharge & $4(2.7 \%)$ \\
Recurrence & \\
After 1 round & $40(27)$ \\
Time to recurrence & \\
After 1 round & $4(0.25-36)^{\mathrm{a}}$ months \\
Number cured & $126(96.9)$ \\
Glue alone $(n=130)$ & $126(86)$ \\
Total cohort $(n=146)$ &
\end{tabular}

${ }^{\mathrm{a}}$ Median (range) 
0.25-36) months. Of the 19 patients who had had previous surgery, $14(73.7 \%)$ were cured after 1 application of fibrin glue. Twenty-four (60\%) of those with recurrence decided to have repeat glue treatment after consideration of available options and 4/24 (16.6\%) subsequently had recurrence. The remaining 16 with recurrence decided to have excisional surgery after consideration of the available options: $13 \mathrm{had}$ a Karydakis procedure, 2 had a wide excision and healing by secondary intention and 1 had midline excision and closure. Following excisional surgery, 7/16 (43.8\%) had recurrence. Cumulative healing after 2 rounds of treatment with fibrin glue alone was 126/130 (96.9\%).

\section{Discussion}

We have shown that curettage of the sinus with fibrin glue obliteration is a successful first line technique for the vast majority of patients with PSD, with long- term healing seen in $2 / 3$ after 1 glue treatment, rising to $97 \%$ after 2 rounds of treatment. Recurrence after previous surgery for PSD was also successfully treated using fibrin glue.

Wound complications, long healing times, recurrence, infection and pain result in a low quality of life after traditional surgery for PSD [20, 21, 32]. Wound healing by secondary intention (either after wide excision or break down of a primarily closed wound) places a heavy burden on community nursing, is costly and causes significant delay to return to normal activities [28]. We have previously demonstrated that fibrin glue treatment causes little postoperative pain, few complications, rapid return to normal activity and is liked by patients [21, 28, 30]. The procedure is quick, requires little technical expertise and junior surgeons can be trained quickly to perform it. When recurrence does occur, as it may after any treatment for PSD, all options, including repeat fibrin glue, are available.

Whilst a recurrence rate of $27 \%$ after one treatment might seem initially disappointing, it is not out of line with other reports using much more invasive treatments [2, 20, 22-24]. However, an overall cure rate of $96.9 \%$ in virtually all comers in a relatively large series does seem of interest. Isik et al. used a similar technique in a study of 40 patients and found a $90 \%$ cure rate at 1 year after 1 application [25]. Smith et al. in a study of 41 children compared 10 who had primary pit excision and fibrin glue injection to 26 who had a lateralising flap technique. Operative time was significantly lower in the glue group but recurrence infrequent and similar between groups. There were 2 (20\%) recurrences in the glue group who had curative repeat application [27].

Our results are also comparable to chemical therapies for PSD. Bayhan et al., used a minimal excision technique and phenol injection and reported a $94.5 \%$ cure rate [34].
Another study using a mixture of henna powder and tetracycline in petroleum jelly reported healing in $89 \%$ of patients with PSD after application of the mixture to the tract in outpatients [35]. Other, minimally invasive procedures for PSD, such as endoscopic pilonidal sinus treatment (EPSiT) and fistula laser closure (FiLaC) report good outcomes but require special and expensive instrumentation and training $[10,36]$. Common surgical procedures for PSD are associated with an overall recurrence rate of 7\% [17]. Our results were similar but without the previously discussed complications.

Isik et al. suggested that fibrin glue should only be used as primary treatment for PSD in patients with no prior history of infection or surgical treatment [25]. In our study, 19 patients had previously had surgery for PSD. Fourteen of these $(73.7 \%)$ were successfully treated after one round of glue. The only complication reported was seen in 4 (2.7\%) patients who developed discharge from the glue site and were treated conservatively, with no subsequent recurrence. Care should be taken during curettage as retention of products is a leading cause of recurrence [30].

We recognise that some patients may have developed recurrence but may not have returned to our centre. In addition, it is not known how long patients with PSD should be followed up before being considered free of the risk of recurrence and one study has suggested 20 years [37], obviously beyond the scope of most investigators [20, 25, 30]. However, keeping young and otherwise active patients under review for long periods is not cost effective and burdensome to secondary healthcare; symptoms are sufficiently troubling that those with recurrence will seek review without formal follow- up. However, careful consideration should be given to the length of follow- up in any randomised trial comparing different treatments for PSD.

A recent Cochrane Review found that current evidence is of low quality and uncertain regarding any benefits associated with the use of fibrin glue as monotherapy or as an adjunct to surgery in PSD [32]. Large, high quality randomised trails are required, including patient preference and satisfaction as end points, along with complication and recurrence. These should also include a thorough economic evaluation to include costs to primary and secondary care and the wider impact to society of lost work days for each treatment.

\section{Conclusions}

Fibrin glue application for PSD is a quick procedure requiring little technical expertise or equipment and no requirement for patient aftercare. Fibrin glue shows promise as an effective first and second line treatment for PSD. 


\section{Compliance with ethical standards}

Conflict of interest The authors declare that they have no conflict of interest.

Ethical approval All procedures performed were in accordance with the ethical standards of the responsible committee on human experimentation (institutional and/or national) and with the Helsinki Declaration of 1975 as revised in 2000.

Informed consent For this type of study, formal consent is not required.

Open Access This article is distributed under the terms of the Creative Commons Attribution 4.0 International License (http://creativeco mmons.org/licenses/by/4.0/), which permits unrestricted use, distribution, and reproduction in any medium, provided you give appropriate credit to the original author(s) and the source, provide a link to the Creative Commons license, and indicate if changes were made.

\section{References}

1. Chintapatla S, Safarani N, Kumar S, Haboubi N (2003) Sacrococcygeal pilonidal sinus: Historical review, pathological insight and surgical options. Tech Coloproctol 7:3-8

2. McCallum IJD, King PM, Bruce J (2008) Healing by primary closure versus open healing after surgery for pilonidal sinus: systematic review and meta-analysis. BMJ 336:868-871

3. Loganathan A, Arsalani Zadeh R, Hartley J (2012) Pilonidal disease. Dis Colon Rectum 55:491-493

4. Kaya B, Eris C, Atalay S, Bat O, Karabulut K, Bulut N et al (2012) Modified Limberg transposition flap in the treatment of pilonidal sinus disease. Tech Coloproctol 16:55-59

5. Pronk AA, Eppink L, Smakman N, Furnee EJB (2018) The effect of hair removal after surgery for sacrococcygeal pilonidal sinus disease: a systematic review of the literature. Tech Coloproctol 22:7-14

6. Bosche F, Luedi MM, van der Zypen D, Moersdorf P, Krapohl B, Doll D (2018) The hair in the sinus: sharp-ended rootless head hair fragments can be found in large amounts in pilonidal sinus nests. World J Surg 42:567-573

7. Gosselink MP, Jenkins L, Toh JWT, Cvejic M, Kettle E, Boadle RA et al (2017) Scanning electron microscope imaging of pilonidal disease. Tech Coloproctol 21:905-906

8. Thompson MR, Senapati A, Kitchen P (2011) Simple day-case surgery for pilonidal sinus disease. Br J Surg 98:198-209

9. Bascom J (1980) Pilonidal disease: origin from follicles of hairs and results of follicle removal as treatment. Surgery 87:567-572

10. Athem TT, Arulampalam RT (2018) Outcomes of endoscopic pilonidal sinus treatment (EPSiT): a systematic review. Tech Coloproctol 22:325-331. https://doi.org/10.1007/s1015 1-018-1803-4

11. Salih AM, Kakamad FH, Salih RQ, Mohammed SH, Habibullah IJ, Hammood ZD et al (2018) Nonoperative management of pilonidal sinus disease: one more step toward the ideal management therapy - a randomized controlled trial. Surgery. https:// doi.org/10.1016/j.surg.2017.12.014 (Published Online First: March)

12. Allen-Mersh TG. Pilonidal sinus: finding the right track for treatment. 1990; 77:12-132

13. Lund JN (2017) Less is more in the treatment of pilonidal sinus disease. Dis Colon Rectum 60:e1
14. Webb PM, Wysocki AP (2011) Does pilonidal abscess heal quicker with off-midline incision and drainage? Tech Coloproctol 15:179-183

15. Seleem MI, Al-Hashemy AM (2005) Management of pilonidal sinus using fibrin glue: a new concept and preliminary experience. Color Dis 7:319-322

16. Yoldas T, Karaca C, Unalp O, Uguz A, Caliskan C, Akgun E et al (2013) Recurrent pilonidal sinus: lay open or flap closure, does it differ? Int Surgery 98:319-323

17. AL-Khamis A, McCallum I, King PM, Bruce J (2010) Healing by primary versus secondary intention after surgical treatment for pilonidal sinus. Cochrane Database Syst Rev. https://doi. org/10.1002/14651858.CD006213.pub3 (Published Online First: 20 January)

18. Can MF, Sevinc MM, Hancerliogullari O, Yilmaz M, Yagci G (2010) Multicenter prospective randomized trial comparing modified Limberg flap transposition and Karydakis flap reconstruction in patients with sacrococcygeal pilonidal disease. Am J Surg 200:318-327

19. Milone M, Velotti N, Manigrasso M, Anoldo P, Milone F, De Palma GD (2018) Long-term follow-up for pilonidal sinus surgery: A review of literature with metanalysis. Surgury. https ://doi.org/10.1016/J.SURGE.2018.03.009 (Published Online First: 24 April)

20. Greenberg R, Kashtan H, Skornik Y, Werbin N (2004) Treatment of pilonidal sinus disease using fibrin glue as a sealant. Tech Coloproctol 8:95-98

21. Elsey E, Lund JN (2013) Fibrin glue in the treatment for pilonidal sinus: high patient satisfaction and rapid return to normal activities. Tech Coloproctol 17:101-104

22. Handmer M (2012) Sticking to the facts: a systematic review of fibrin glue for pilonidal disease. ANZ J Surg 82:221-224

23. Keshava A, Young CJ, Rickard MJFX, Sinclair G (2007) Karydakis flap repair for sacrococcygeal pilonidal sinus disease: how important is technique? ANZ J Surg 77:181-183

24. Keshvari A, Keramati MR, Fazeli MS, Kazemeini A, Meysamie A, Nouritaromlou MK (2015) Karydakis flap versus excisiononly technique in pilonidal disease. J Surg Res 198:260-266

25. Isik A, Eryılmaz R, Okan I, Dasiran F, Firat D, Idiz O et al (2014) The use of fibrin glue without surgery in the treatment of pilonidal sinus disease. Int J Clin Exp Med 7:1047-1051

26. Khanna A, Rombeau JL (2011) Pilonidal disease. Clin Colon Rectal Surg 24:46-53

27. Smith CM, Jones A, Dass D, Murthi G, Lindley R (2015) Early experience of the use of fibrin sealant in the management of children with pilonidal sinus disease. J Pediatr Surg 50:320-322

28. Liptrot S, Leveson S, Lund J (2008) Fibrin glue may be better than surgery for pilonidal sinus: results of a prospective, randomized, controlled trial and 2-year follow up. Dis Colon Rectum 51:710-711

29. Spotnitz W. Commercial fibrin sealants in surgical care. Am J Surg 2001; 182:S8-S14

30. Lund JN, Leveson SH (2005) Fibrin glue in the treatment of pilonidal sinus: results of a pilot study. Dis Colon Rectum 48:1094-1096

31. Hardy E, Herrod P, Sian T, Boyd-Carson H, Blackwell J, Lund $\mathrm{J}$ et al (2018) Fibrin glue obliteration is safe, effective and minimally invasive as first line treatment for pilonidal sinus disease in children. J Pediatr Surg. https://doi.org/10.1016/J.JPEDS URG.2018.07.024 (Published Online First: 8 September)

32. Lund J, Tou S, Doleman B, Williams JP (2017) Fibrin glue for pilonidal sinus disease. Cochrane Database Syst Rev. https:// doi.org/10.1002/14651858.CD011923.pub2 (Published Online First: 13 January) 
33. Welcome to the TISSEEL [Fibrin Sealant] Sealing Stops Bleeding. http://www.tisseel.com/us/index.html. Accessed 14 Jan 2018

34. Bayhan Z, Zeren S, Duzgun SA, Ucar BI, Alparslan Yumun HN, Mestan M (2016) Crystallized phenol application and modified Limberg flap procedure in treatment of pilonidal sinus disease: a comparative retrospective study. Asian J Surg 39:172-177

35. Salih AM, Kakamad FH, Salih RQ, Mohammed SH, Habibullah IJ, Hammood ZD et al (2018) Nonoperative management of pilonidal sinus disease: one more step toward the ideal management therapy - a randomized controlled trial. Surgery (Published Online First: March). https://doi.org/10.1016/j. surg.2017.12.014

36. Dessily M, Charara F, Ralea S, Allé J-L (2017) Pilonidal sinus destruction with a radial laser probe: technique and first Belgian experience. Acta Chir Belg 117:164-168

37. Doll D, Krueger CM, Schrank S, Dettmann H, Petersen S, Duesel W (2007) Timeline of recurrence after primary and secondary pilonidal sinus surgery. Dis Colon Rectum 50:1928-1934 